\title{
Including Social and Behavioral Determinants in Predictive Models: Trends, Challenges, and Opportunities
}

Marissa Tan ${ }^{1}$, MPH, MD; Elham Hatef ${ }^{1,2,3}$, MD, MPH, FACPM; Delaram Taghipour ${ }^{1}$, MPH, MBA, MD; Kinjel Vyas $^{4}$, MS; Hadi Kharrazi ${ }^{2,4}$, PhD, MD; Laura Gottlieb ${ }^{5}$, MPH, MD; Jonathan Weiner ${ }^{2}$, DrPH

\footnotetext{
${ }^{1}$ General Preventive Medicine Residency Program, Johns Hopkins Bloomberg School of Public Health, Baltimore, MD, United States

${ }^{2}$ Department of Health Policy and Management, Johns Hopkins Bloomberg School of Public Health, Center for Population Health Information Technology, Baltimore, MD, United States

${ }^{3}$ Department of Health Policy and Management, Johns Hopkins Bloomberg School of Public Health, Baltimore, MD, United States

${ }^{4}$ Division of Health Sciences Informatics, Johns Hopkins School of Medicine, Baltimore, MD, United States

${ }^{5}$ Social Interventions Research and Evaluation Network, Center for Health \& Community, University of California, San Francisco, CA, United States
}

\section{Corresponding Author:}

Elham Hatef, MD, MPH, FACPM

Department of Health Policy and Management

Johns Hopkins Bloomberg School of Public Health

Center for Population Health Information Technology

624 N. Broadway, Room 502

Baltimore, MD, 21205

United States

Phone: 14109788006

Email: ehatef1@jhu.edu

\begin{abstract}
In an era of accelerated health information technology capability, health care organizations increasingly use digital data to predict outcomes such as emergency department use, hospitalizations, and health care costs. This trend occurs alongside a growing recognition that social and behavioral determinants of health (SBDH) influence health and medical care use. Consequently, health providers and insurers are starting to incorporate new SBDH data sources into a wide range of health care prediction models, although existing models that use SBDH variables have not been shown to improve health care predictions more than models that use exclusively clinical variables. In this viewpoint, we review the rationale behind the push to integrate SBDH data into health care predictive models and explore the technical, strategic, and ethical challenges faced as this process unfolds across the United States. We also offer several recommendations to overcome these challenges to reach the promise of SBDH predictive analytics to improve health and reduce health care disparities.
\end{abstract}

(JMIR Med Inform 2020;8(9):e18084) doi: 10.2196/18084

\section{KEYWORDS}

social determinants of health; information technology; health care disparities; population health

\section{Social and Behavioral Determinants of Health and Predictive Analytics}

Since the Health Information Technology for Economic and Clinical Health act of 2009, the majority of US health care systems have adopted electronic health records (EHRs) for patient care [1]. Faced with increased financial incentives to improve population health, care coordination, and quality of care, health care providers and payers now use EHRs and other digital data sources to understand how past associations and trends in their patient populations can be used to forecast health

care-related outcomes, a component of the widely known strategy of predictive analytics $[1,2]$.

Predictive analytics uses extensive data, modeling, and algorithms to predict individual and population events and has a long history in commercial industries [3]. For better or worse, commercial industries have developed innovative techniques to mine demographic, socioeconomic, and consumer behavior data as part of the forecasting and analytics process. For example, web-based sellers and banks collect personal information on purchase histories, credit data, consumer behaviors, and life events that are available in various digital databases. These institutions use such data to make predictions 
for various goals, such as determining ideal customers for specific products or services and how much institutions should offer to whom [4].

There are 2 broad approaches to predictive analytics. The modeling and simulation approach is used to test hypotheses or assess the consequences of scenarios where the rules of the models are developed from theories. Such models also employ data to initialize variables, to calibrate free parameters, or for validation. Alternatively, predictive analytics may also use machine learning in which models are exclusively built from data via algorithms and tested on data that mirror the calibration and validation steps of modeling and simulation, respectively. These approaches can be combined in complex systems [5]. This paper focuses on machine learning and provides several observations that apply to modeling and simulation. Generally, the modeling and simulation approach is useful in systems where the dynamics are well known, whereas machine learning is useful when accurate simulations cannot be performed and there are enough data to determine a model [5]. On the basis of the specific prediction goal, different types of data and methods are required and thus have different associated limitations and challenges.

In health care, the same techniques are used with different goals. Over the last decade, health insurance plans have ramped up the use of predictive analytics, employing patient demographics, insurance claims data, and clinical characteristics derived from EHRs to create statistical models of future health care risks and resource utilization [6]. Analysts have also developed predictive models for health and health care. These data science techniques generally involve larger and more complex databases but represent an application of traditional statistical forecasting methods using a wide range of techniques such as deep neural networks, natural language processing (NLP), random forest, and decision tree algorithms $[7,8]$.

The growing awareness of associations between social and behavioral factors and health has led predictive modeling to explore the incorporation of social and behavioral determinants of health (SBDH) into forecasting $[9,10]$. For example, on an individual level, diet and physical activity affect health care use and costs $[11,12]$. At the community level, characteristics of neighborhoods, such as food access and transportation, play significant roles in health outcomes, morbidity, and mortality [13-15].

Although SBDH factors have been incorporated in the predictive modeling process to forecast health care-related outcomes, there are limitations related to the use of such factors. For instance, machine learning methods are not generally developed to capture changing SBDH factors. They mainly address the stationary distributions of the SBDH factors. A change in the data requires providing longitudinal data to the model to perform time series modeling and to capture these changes. If a change in the distribution of data is necessary (eg, to reflect potential trends in SBDH over time), then the approach of modeling and simulation may be used to explore various scenarios. An example is the common use of event-driven simulations in health care research [16].
A growing crop of initiatives uses SBDH to predict health care use in the United States [17]. Although the methods and evidence underlying these new models that incorporate SBDH are nascent and have not shown improved predictions over traditional clinical measures, the medical community's interest in SBDH needs in conjunction with predictive analytics continues to increase [18,19].

\section{The Rationale for Including Social and Behavioral Determinants in Predictive Models}

Studies in the United States and worldwide have suggested that SBDH, such as educational attainment, have a greater impact on premature mortality than clinical care access and quality $[10,20]$. A meta-analysis in the United States found that income inequality, social support, segregation, individual and neighborhood poverty, and education level were responsible for $50 \%$ of deaths [9]. Some literature on mortality estimates the lack of quality medical care to encompass $10 \%$ to $20 \%$ of deaths [10,21,22]. Entities such as the World Health Organization have recognized the role of SBDH factors in health equity and committed to action on these determinants [23].

Several national agencies have recognized and advocated for the incorporation of SBDH into health care practices and the standard use of health data. The National Academies of Science, Engineering, and Medicine have identified 5 complementary activities that can facilitate the integration of social care into health care. These activities include the following: "(1) identify the social risks and assets of defined patients and populations; (2) focus on altering clinical care to accommodate identified social barriers; (3) reduce social risk by assisting in connecting patients with relevant social care resources; (4) understand existing social care assets in the community, organize them to facilitate synergies, and invest in and deploy them to positively affect health outcomes; and (5) work with partner social care organizations to promote policies that facilitate the creation and redeployment of assets or resources to address health and social needs." [24] Moreover, the eHealth initiative, a national coalition focused on health data interoperability in the United States, advocates the use of SBDH data to coordinate care, evaluate interventions that address social needs, identify gaps in community resources, predict health risk, and develop SBDH-sensitive interventions to improve health [25].

\section{Potential Benefits of Including Social and Behavioral Determinants in Predictive Models}

Bolstered by the initiatives of the national organizations, incorporation of SBDH into predictive models could help to (1) identify patients and populations who need more resources, (2) improve health care reimbursement for providers who serve patients with social needs, (3) reduce health and health care disparities, and (4) improve the quality of health care.

Predictive analytics and SBDH risk segmentation could facilitate efforts to identify patients who would benefit from more resources and targeted services. This may lessen the resource burden of universal social risk screening or social care delivery 
[26]. For example, a systematic risk analysis could help identify patients with modifiable social risks at a higher risk of poor medical outcomes. This type of segmentation could help health systems target appropriate resources, for example, referrals to case management, social service agencies, or government support programs such as the Supplemental Nutrition Assistance Program [27-29]. In addition to using SBDH-sensitive analytics to identify vulnerable individuals, this approach could also help health care organizations or partner agencies identify disadvantaged communities, such as neighborhoods with food deserts $[26,30]$. A health care system truly desiring to maximize its impact on the health of a community could more effectively increase food access at the neighborhood level by working with farmers' markets and grocery stores in addition to individual-level interventions.

Under the present federal regulations for Medicaid-managed care, social and behavioral services such as care coordination are reimbursed through capitation. Predictive analytics and SBDH risk segmentation could support new payment models to adequately reflect the medical and social complexity of patients [31]. Beyond capitated or global payments, contextualizing patients with their SBDH needs enables health care payers to more accurately assess providers' care for vulnerable populations who require more health care resources, thus impacting their fee-for-service payments [27]. Present Medicaid-managed care regulations could support value-added services that would not be reimbursed under capitation alone but would address the health needs of members, such as interventions that assess environmental triggers of asthma [31]. Several states (eg, Rhode Island, Minnesota, and Oregon) have adopted the Accountable Care Organization models that reward health care providers for addressing their Medicaid populations' SBDH with adjusted payment structures [32,33]. Patient protection laws in the United States regarding insurance denials and premium payments should be upheld to ensure that SBDH risk segmentation does not increase the burden of health care costs to disadvantaged populations [34].

Identifying and accounting for the increased risk of poor health outcomes and associated health care utilization is critical to the elimination of disparities in care for vulnerable populations. The spread of COVID-19 across the United States and worldwide is a great example of how predictive modeling could help health care systems and public health officials address health disparities and potentially change the course of the pandemic. The COVID-19 pandemic has highlighted long-standing health disparities [35,36]; neighborhoods with the highest proportion of racial and ethnic minorities and people living in poverty are experiencing higher rates of hospitalization and death [37-40]. In response, several research teams have started to include information on SBDH in predictive modeling and assessment of COVID-19-related risk and outcomes [39,41]

Exclusion of SBDH-related variables in risk-adjusted reimbursement models would result in lower reimbursement for patients with greater social needs, which dissuades providers from caring for these patients in capitated systems [42] Employing SBDH in risk-adjusted capitated payment models could translate into improved health care policy by supporting organizations to more effectively meet the needs of individuals and communities with greater social needs.

Beyond payment adjustment, stratifying patients by their SBDH risk levels could reveal health disparities as well as promote health care quality by establishing a mechanism to fairly evaluate providers' care of patients with social disadvantages [42]. Health systems and payers could further evaluate the quality of health care by developing specific SBDH-dependent quality indicators that bolster equity in health care across the range of patients served [42].

\section{Present State of Including Social and Behavioral Determinants in Predictive Analytics}

Although there is a strong and compelling body of literature on the observed associations between SBDH and health, to date, diagnosis-based forecasting models used to predict cost and utilization have not yet shown the incremental value of adding SBDH risk factors to predictions. Some published reports using community-level SBDH data contribute only slightly to the predictive model performance beyond individual patient characteristics extracted from EHR data [43,44].

Similarly, SBDH-oriented predictive models using newer applications of machine learning techniques have shown varying levels of performance in predictions. A neural network predictive model that incorporates SBDH was found to identify, with $78 \%$ accuracy, over two-third of the Medicare patients in their sample who would not respond to automated medication refill requests and may benefit from targeted outreach [45]. Seligman et al [46] applied linear regression and different machine learning techniques to predict systolic blood pressure, BMI, waist circumference, and telomere length using SBDH variables of gender, income, wealth, education, public benefits, family structure, and health behaviors. Although neural networks outperformed other machine learning techniques as fit for their sample, most of their tested machine learning models performed similar to the simpler regression models, and all models had poor out-of-sample prediction [46]. Applying random survival forest methods to develop a predictive model using the poverty status and EHR data, Bhavsar et al [44] did not find that risk prediction for health care services and hospitalization outcomes improved beyond models using traditional EHR data. Similarly, a machine learning model using random forest decision methods on structured and unstructured SBDH only improved sensitivity $(67.6 \%)$ by $0.1 \%$ and showed decreased specificity $(69.6 \%)$ by $1.9 \%$ compared with their tested non-SBDH models in predicting referrals for social needs [47].

Given the evidence-based expectation that SBDH should improve predictive models, why have published predictive models not shown enhanced predictions? Although insufficient data and suboptimal methods are potential explanations common to all research, triple challenges unique to the SBDH context include the diversity of data sources and health outcomes used in existing models as well as the lack of transparency, which together pose an important question about model accuracy. 


\section{Diversity of Data Sources}

A wide range of SBDH variables and data sources are used in predictive models and no guidelines exist to distinguish which variables and data sources would best improve the performance of the predictive model. A rapid review of social, behavioral, and environmental determinants of health used with clinical data identified 744 variables among 178 articles, in which the majority of articles included socioeconomic and material conditions [48]. Data sources vary from individual-level EHR data and insurance claims to community-level data from the United States census and similar sources as well as commercial data such as information from credit reporting agencies.

Health plans have historically used insurance claims, which include diagnostic and prior utilization information of varying completeness across health care settings, for predictive modeling to forecast utilization and cost [27,49]. More recently, health payers and other private health care companies have obtained consumer and financial data, such as information on household size, income, and wealth measures, from credit reporting agencies to better assess their members' needs [27,29,50]. For instance, one company mines public data on education, law enforcement records, birth records, voter registration, and derogatory records such as a history of evictions and liens [27].

Rather than commercial data, academic centers and government organizations have primarily relied on individual-level clinical information derived from structured and unstructured EHRs [51] and relevant risk factors on a community level extracted from public surveys [52], such as the United States Census Bureau American Community Survey, which includes multiple indicators of neighborhood deprivation [43,53]; the Food Access Research Atlas, which describes food deserts [54,55]; and the American Housing Survey, which contains information on housing characteristics [56,57]. In one systematic review of predictive models using EHR data, 36 of the 106 unique studies included SBDH data in one of their final predictive models [58]. However, the social determinants included were limited to race or ethnicity alone in 19 of the 36 EHR-based studies [58]. The same systematic review included behavioral determinants in 30 of these EHR-based predictive models. However, 12 of these studies' behavioral variables were limited to tobacco use or smoking alone [58]. As another case example, a Kaiser predictive model that uses race and ethnicity as one variable to develop a hypoglycemia risk model omitted race in their final, simpler model on finding that race was not one of the strongest predictors of hypoglycemia compared with clinical factors [59]

In addition to survey-collected data aggregated at the geographic level, academic centers are expanding this community-level framework to include geocentric data such as transit data, which contains data on access to transportation [60], the Environmental Protection Agency's Air Quality Index data [61], and food desert data from the United States Department of Agriculture's Food Access Research Atlas [62].

As expected with predictive models, the performance of a model varies depending on the selected SBDH variables and data sources $[43,44]$. When analyzing SBDH variables, the diversity of data sources has implications for a model's ability to address challenges associated with SBDH, such as accurately assessing the temporal duration of SBDH and determining the spatial-level effects of population-level SBDH data. Researchers need to critically analyze SBDH variables and data sources to ensure the selection of variables and high-quality data sources that accurately and authentically capture SBDH factors to be tested.

\section{Diversity of Health Outcomes}

Health care-based predictive models that integrate SBDH risk factors have been used to forecast a wide range of health care-relevant endpoints. Although, most often, the predicted outcomes include health care costs and utilization, such as emergency department visits, hospitalizations, and readmissions $[27,44,63,64]$. There is no consensus on which health outcomes are the most appropriate to predict with specific SBDH factors. Within the public health, academic, and health policy sectors, models have expanded their focus outside the realm of medical care. For example, the Centers for Disease Control and Prevention (CDC), the CDC Foundation, and the Robert Wood Johnson Foundation collaboratively created 500 Cities, a tool that uses community-level socioeconomic characteristics to predict city-level health behaviors, mortality, and morbidity $[65,66]$.

Similar to challenges related to data sources, the diversity of health outcomes as the endpoint for the predictive models will impact assessing the performance of their methods and determining the best methods to address specific SBDH variables or to set the stage for standardized guidelines for specific SBDH variables and outcomes.

\section{Lack of Transparency}

Many predictive models that incorporate SBDH data have been developed and are used in the private sector and are therefore not only proprietary but also unavailable for public review and scrutiny. Consequently, other researchers cannot replicate the methods used in these predictive models. Several predictive modeling companies that have made use of only clinical risk factors now extensively market the inclusion of SBDH data in their predictive risk models [27,29,50]. One company relies exclusively on consumer data, rather than medical data, to develop as many as 70 different models to predict patients at risk for general poor health and high health care costs [67]. For example, one commercial model developer described a case study using its socioeconomic score model to predict the risk of common chronic diseases, highlighting the score's successful prediction in the top $10 \%$ and bottom $10 \%$ of the score risk data, although it did not describe how the model performed in the remaining $80 \%$ of the population covered [68].

However, the lack of transparency also extends to the academic sector. When data used for a data-driven model, source code, and the model itself are not made open source, the derived models cannot be replicated, a problem known as the reproducibility crisis in machine learning [69]. When available, analysts would ideally search out the code and data for models in code repositories to learn how models are organized [70]. However, in a survey of 400 artificial intelligence conference papers with algorithms, only $6 \%$ shared the code and about one-third shared their data [69]. Reasons for avoiding sharing range from dependence on another unpublished code and desire 
to maintain a competitive advantage to its proprietary nature or institutional review board restrictions [69]. Without the training data and code, the reproducibility of machine learning is dismal.

Given the relative novelty of SBDH in predictive analytics and the lack of standardization around data sources and outcomes assessed as well as challenges related to transparency of models in the private sector, models that incorporate SBDH factors are fraught with questions about accuracy. The lack of transparency makes it very difficult to assure model accuracy, precludes replicability, and portends clinicians' mistrust of these models. Such challenges highlight the need for greater transparency in model development and sharing across institutions.

\section{Recommendations to Address Challenges and Improve SBDH Predictive Models}

Advancing SBDH predictive analytics will require overcoming several challenges. As the field of health care predictive modeling grows, the incorporation of SBDH factors into predictions will face challenges similar to those of traditional models. Predictive models should follow guidelines in the Transparent Reporting of a multivariate prediction model for Individual Prognosis or Diagnosis (TRIPOD) initiative [71]. The TRIPOD guidelines are concerned with how general health care predictive models are reported and serve as the framework for predictive model development, validation, and modification in health care contexts [71]. This initiative was developed in response to the growing field of health-related predictive analytics and concerns about the lack of transparency, standardization, and oversight [72]. As the field of health care predictive analytics matures, it is time to apply the TRIPOD initiative's guidelines to this rapidly evolving area of health services analytics regarding SBDH factors. Consequently, we offer several recommendations to advance the use of SBDH in health and health care predictive analytics (Textbox 1).

Textbox 1. Recommendations to advance the use of social and behavioral determinants of health in health care predictive analytics.

Privacy standards, patient consent, and ethical use of social and behavioral determinants of health (SBDH) data

- Develop consensus on transparency, privacy protections, and ethical uses of SBDH data in predictive models

- Create guidelines to reduce inherent bias in predictive models

Technical challenges associated with SBDH data sources and analytics

- Determine best practice guidelines for SBDH data sources and predictive model design as well as open-source access

- $\quad$ Expand standardized coding and taxonomies of SBDH risk factors that enhance interoperability

Expanding the knowledge base to inform best practice guidelines for SBDH analytics

- Support national shared research and development to advance the SBDH predictive model development and application

- Establish a national agenda to create a shared evidence base regarding the importance of SBDH factors and the best approach for including SBDH in analytics

\section{Privacy Standards, Patient Consent, and Ethical Use of Social and Behavioral Determinants Data}

\section{Develop Consensus on Transparency, Privacy Protection, and Ethical Uses of SBDH Data in Predictive Models}

As expected, many consumers are unsettled by the unregulated use of personal and commercial information to predict sensitive behaviors or health outcomes [4]. An example of such unregulated use of personal information is Google's acquisition of large amounts of personal health data, from hospitals and clinics across 21 US states, used to predict health and health care use, undisclosed to patients and other parties $[73,74]$. Social determinants cover sensitive topics, such as poverty, substance misuse, food insecurity, and homelessness. Individuals may fear stigmatization from health providers in revealing their SBDH information [75]. Similarly, individuals may be concerned about the social, employment, and legal effects of revealing SBDH when their data are not protected [75].

To address such concerns, there needs to be an established discourse leading to a national consensus and clear guidelines regarding the ethical use of patients' SBDH data in the context of a health care predictive model [76]. Lack of transparency in methods, applications, and data protection results in little accountability to ensure that SBDH risk predictions are not used to achieve profits at the expense of health care quality or access, such as using SBDH data to exclude vulnerable patients from a health intervention to ensure greater health care profits [76,77]. Establishing robust and meaningful national guidelines for using SBDH data will require insights from a variety of clinical, social science, and technical perspectives as well as views of patients, community members, policy makers, and ethicists. In particular, patients should participate and be involved in the research that is developing models to safeguard the ethical and transparent use of patient data [78]. Without the perspectives of patients and community members at the forefront of these discussions, rather than moving to a new level of health care equity and access, SBDH predictive analytics could easily slide into domains that many would consider inappropriate use, especially given a special concern and focus on the highest risk members of our communities [76].

\section{Create Guidelines to Reduce Inherent Bias in Predictive Models}

One important ethical and technical challenge of SBDH analytics, mostly in the application of statistical modeling, is 
ingrained model bias. For instance, vulnerable patients, such as those with more social and behavioral risk factors, may not be adequately represented in the data sources used to build the predictive model, leading to the model's inaccurate predictions for these individuals. Machine learning models on the other hand can address this issue through over- or undersampling. Therefore, being at risk for bias from the original sample is normally corrected in a standard process [79].

The data sources might also lack information on the key SBDH variables that affect the desired outcomes. An example of this challenge might be a predictive model that focuses on health care utilization as the desired outcome and lacks data on health care access for vulnerable populations. Such a model may indicate that individuals with poor access to health care have a low likelihood of future utilization. A model with such ingrained bias would thus underestimate the actual requirement for the greater amount of health care resources necessary to achieve the same health outcomes once these individuals have access to health care [42]. Recently, this situation was observed in a study by Obermeyer et al [80] who assessed a large, commercial health plan's predictive algorithm. The model systematically underestimated the health needs of African American patients by assuming that health care costs served as an adequate proxy for health needs. The bias arose because the unequal access to care among African American patients resulted in less money spent caring for those patients compared with White patients.

Although many researchers use health care utilization and costs as outcomes for SBDH research, models with these outcomes, proxied for health needs, are biased in that the data underrepresents those with lower access to health care. In recognition of the ingrained model bias, one approach might be to develop guidelines that recommend stratifying the population for key SBDH risk factors. Therefore, separate models would assess health care utilization for each stratum, taking into account unmeasured SBDH risk factors impacting health care utilization (eg, socioeconomic status, which defines insurance type and access to health care).

\section{Technical Challenges Associated With Data Sources and Analytics}

\section{Determine Best Practice Guidelines for SBDH Data Sources and Predictive Model Design As Well As Open-Source Access}

The future of SBDH-centric predictive modeling faces several challenges related to data sources and model design. One big data-related challenge is that most social and behavioral data found within providers' EHRs are unstructured, free-text clinical notes and are not standardly interoperable. Although ubiquitous, this information is captured inconsistently and depends on the use of NLP to render the data useful in analytics $[81,82]$. When NLP is utilized, the SBDH language in the health record may not describe the level of SBDH precisely enough to accurately determine social risk as social determinants such as neighborhood disadvantage may need to reach a threshold to have a significant impact on health-related outcomes [83].

Another important challenge is related to the use of population-level SBDH variables and whether such variables are interpreted as proxies for individual-level factors that cannot be measured, such as low household income, or represent population-level spatial elements, such as a high concentration of low household income in a neighborhood [84]. Proxies are based on assumptions to confer population-level characteristics to an individual. In contrast, geospatial models investigate population-level elements based on the principle of spatial autocorrelation, meaning that data located close together are interrelated by nature [85]. Addressing this challenge is critical to the interpretation of models and requires sufficiently transparent models that allow the proper distinction between the two implications of the population-level SBDH variables.

There are also several technical challenges related to the analytic approach, spanning the choice of analytic model, data sources, discriminatory power, and SBDH temporality. Statistical models, spatial analysis, and machine learning have all been used alone and in combination with various SBDH predictive models. Most often, health care predictive analytics uses regression models for their simplicity and acceptability [86]. However, machine learning models may be useful for finding new dimensions that can accurately classify outcomes according to their predictive characteristics in nonlinear data [86]. However, not all machine learning techniques, which range from transparent decision tree algorithms to unsupervised neural networks, are appropriate for use with SBDH predictive models. Highly autonomous machine learning models may select characteristics that are not clinically relevant for the outcome (eg, family meetings as a predictive characteristic for hospital mortality) when researchers do not remove these characteristics [86]. Models should instead reflect appropriate domain expertise as well as appropriate machine learning techniques. Moreover, for techniques that depend on unsupervised neural networks, there are long-standing controversies regarding the disadvantages of nontransparent, one-of-a-kind models versus more readily explainable logistic regression models $[7,86]$.

There are also challenges related to using SBDH data at the geographic level in predictive modeling, which are often needed to identify SBDH on a population level and for community-level interventions [26]. Geospatial analysts need to choose the appropriate granularity for a model, which may be associated with a model's discriminatory power to help distinguish those at high- versus low-risk levels [87]. Furthermore, analyzing SBDH data at different geographic levels (eg, census block group, census tract, county, and state) is methodologically complex.

The discriminatory power to distinguish patients with and without social needs also poses a challenge in nongeospatial modeling with the potential to introduce higher-than-desirable false positives and/or negatives [74]. For instance, a study of food security among Medicare patients using clinical data and a needs assessment survey could not accurately predict which patients would benefit from a referral to community resources [88]. Similarly, a predictive model that uses random forest decision methods applied to socioeconomic data did not improve referral rates to community services once at-risk patients were identified [28]. When SBDH data are operationalized in a poorly functioning algorithm, these false positives and negatives indicate that a health system spends unnecessary resources 
evaluating several patients not at high risk, whereas groups of patients needing social services remain unidentified [74,89]. To address this phenomenon, algorithms may need to be tested with new data as predictive analytics methods that use SBDH risk data have evidenced limited generalizability outside of the original sample data where the model was developed [26,46].

Within a model's discriminatory power is the challenge of temporality in analytic models. Specifically, further research and development are necessary to determine how to capture changing social risk factors related to changing life circumstances throughout a person's life or epoch [90]. For example, by structural design, a model may overlook an individual's loss of income through unemployment or community changes not reflected in neighborhood data [74]. Thus, time-oriented models will be better able to elucidate the persistence or amelioration of disparities.

Further guidance on analytic challenges, such as optimizing the appropriate separation of high- and low-risk cases, will be crucial as part of future, wide-scale dissemination of SBDH-focused predictive modeling tools. To advance predictive analytics and increase generalizability across the United States, there should also be open-source SBDH resources for methods and databases that leverage previous $\mathrm{SBDH}$ research and development [91,92]. Globally, the Research Data Alliance could create a working group to spearhead the creation of open-source SBDH data sources and facilitate work toward interoperability [93].

\section{Expand Standardized Coding and Taxonomies of SBDH Risk Factors That Enhance Interoperability}

Once a single health care system renders SBDH data useful through advanced data science, they must find ways to disseminate these advances. The lack of standardization of SBDH data and collection processes prevents the interoperability and integration of modeling into diverse platforms [91,92] and impacts the creation of SBDH products for EHRs [94]. For greater interoperability, we need a standard, practical coding system for SBDH factors that goes beyond vendor-specific coding $[91,92]$. Such an endeavor is presently being pioneered by the Social Interventions Research and Evaluation Network through the HL7 Gravity Project [95].

\section{Expanding the Knowledge Base to Inform Best Practice Guidelines}

\section{Support National Shared Research and Development to Advance SBDH Predictive Model Development and Application}

In recognition of the emerging field of SBDH predictive analytics, steps toward developing consensus and further evaluative work are needed to produce best practice guidelines for the use of SBDH data in predictive modeling [91]. There is wide variability in the choice of data sources, risk factors, targeted outcomes, geographic levels, and analytic approaches in the SBDH predictive models. Each of these model components can impact a tool's accuracy and appropriateness for use in a particular setting or context. At present, there is a very limited understanding of the impact of these parameters on the effectiveness of the SBDH predictive model. Although endpoints such as health care cost and utilization may seem similar, the choice of health outcome in a model can obscure the path from social risk to health. Best practice guidelines should include transparency of model validation methods for various outcomes to ensure that modeling methods can be replicated in other populations [91]. The use of SBDH variables in predictive modeling is relatively new. Developing consensus might be premature in such circumstances and evaluative work must occur beforehand. However, to form guidelines, it is critical to consider standardization in SBDH predictive analytics and to organize the discourse early on. Such discourse would facilitate data sharing, create open-source tools and algorithms, and set expectations.

\section{Establish a National Agenda to Create a Shared Evidence Base Regarding the Importance of SBDH Factors and the Best Approach for Including SBDH in Analytics}

Although the methods and analyses addressing SBDH have matured substantially over the past decades, an expanded data infrastructure and more research are necessary to gain a full understanding of how SBDH manifests throughout a person's life [96]. Present health analytics platforms are generally not built to advance our knowledge base in this area. Rather, they are often intended to give health systems or insurers a leg-up over their competition in achieving financial or pay-for-performance targets. There should be a national agenda to develop and share technology and human resources and strategies to support efficient data extraction, evidence-based development, and effective analytics and reporting within and across institutions in the United States [92]. For-profit entities also have a vested interest to create better predictive models. Such shared desire would be an incentive for them to participate in the development of a shared evidence base, resulting in the creation of better predictive models.

\section{Conclusions}

In the face of great challenges and perhaps even greater benefits, we have identified a series of potential approaches for advancing the present state of predictive analytics within the SBDH context. The future of predictive modeling involving SBDH will require key stakeholders-including policy makers, payers, providers, researchers and analysts, patients, and their advocates - to reach a consensus regarding ethical frameworks, data sharing, technical parameters, and model transparency. Such a consensus will help ensure that the ultimate promise of SBDH analytics, improving health and reducing health disparities, is achieved in health care systems and communities across the United States.

\section{Acknowledgments}

The work by LB on this project was supported by a grant from the Robert Wood Johnson Foundation. 


\section{Authors' Contributions}

All the authors contributed significantly to the project and writing of the manuscript. All the authors reviewed the final paper and provided comments as deemed necessary. MT drafted the manuscript and revised it using input from other authors. EH supervised the literature review and development of the overall manuscript. MT, DT, and KV performed the literature review and provided a summary of available studies that address SBDH in predictive modeling. HK and LG provided insight into the application of SBDH in predictive analytics. JW was the principal investigator of the project, who designed the overall scope and goals of the study and supervised the day-to-day operations of the project.

\section{Conflicts of Interest}

LG reports receiving funding from the Commonwealth Fund, Episcopal Health Foundation, Kaiser Permanente, NIMHD, and AHRQ for work unrelated to this manuscript. She received support from the Robert Wood Johnson Foundation for her work on this manuscript. The remaining authors declare no conflicts of interest.

\section{References}

1. Digital Data Improvement Priorities for Continuous Learning in Health and Health Care: Workshop Summary. Washington, DC: National Academies Press; 2013.

2. Public Health and Promoting Interoperability Programs. Centers for Disease Control and Prevention. URL: https://www. cdc.gov/ehrmeaningfuluse/introduction.html [accessed 2019-10-26]

3. Engelgau MM, Khoury MJ, Roper RA, Curry JS, Mensah GA. Predictive analytics: helping guide the implementation research agenda at the national heart, lung, and blood institute. Glob Heart 2019 Mar;14(1):75-79 [FREE Full text] [doi: 10.1016/j.gheart.2019.02.003] [Medline: $\underline{31036305]}$

4. Duhigg C. How Companies Learn Your Secrets. The New York Times. 2012. URL: https://www.nytimes.com/2012/02/ 19/magazine/shopping-habits.html [accessed 2019-09-08]

5. Deist T, Patti A, Wang Z, Krane D, Sorenson T, Craft D. Simulation-assisted machine learning. Bioinformatics 2019 Oct 15;35(20):4072-4080 [FREE Full text] [doi: 10.1093/bioinformatics/btz199] [Medline: 30903692]

6. Gurley V. Using Predictive Analytics to Address Social Determinants of Health. Population Health Learning Network. 2018. URL: https://www.managedhealthcareconnect.com/article/using-predictive-analytics-address-social-determinants-health [accessed 2019-09-01]

7. Beam AL, Kohane IS. Big data and machine learning in health care. J Am Med Assoc 2018 Apr 3;319(13):1317-1318. [doi: 10.1001/jama.2017.18391] [Medline: 29532063]

8. Lovis C. Unlocking the power of artificial intelligence and big data in medicine. J Med Internet Res 2019 Nov 8;21(11):e16607 [FREE Full text] [doi: 10.2196/16607] [Medline: 31702565]

9. Galea S, Tracy M, Hoggatt KJ, Dimaggio C, Karpati A. Estimated deaths attributable to social factors in the United States. Am J Public Health 2011 Aug;101(8):1456-1465. [doi: 10.2105/AJPH.2010.300086] [Medline: 21680937]

10. 2019 County Health Rankings Key Findings Report. County Health Rankings \& Roadmaps. 2019. URL: https://www. countyhealthrankings.org/reports/2019-county-health-rankings-key-findings-report [accessed 2020-08-24]

11. Xu X, Bishop EE, Kennedy SM, Simpson SA, Pechacek TF. Annual healthcare spending attributable to cigarette smoking: an update. Am J Prev Med 2015 Mar;48(3):326-333 [FREE Full text] [doi: 10.1016/j.amepre.2014.10.012] [Medline: 25498551]

12. Ley SH, Ardisson Korat AV, Sun Q, Tobias DK, Zhang C, Qi L, et al. Contribution of the nurses' health studies to uncovering risk factors for type 2 diabetes: diet, lifestyle, biomarkers, and genetics. Am J Public Health 2016 Sep;106(9):1624-1630. [doi: 10.2105/AJPH.2016.303314] [Medline: 27459454]

13. Walker RE, Keane CR, Burke JG. Disparities and access to healthy food in the United States: a review of food deserts literature. Health Place 2010 Sep;16(5):876-884. [doi: 10.1016/j.healthplace.2010.04.013] [Medline: 20462784]

14. Leonardi C, Simonsen NR, Yu Q, Park C, Scribner RA. Street connectivity and obesity risk: evidence from electronic health records. Am J Prev Med 2017 Jan;52(1S1):S40-S47. [doi: 10.1016/j.amepre.2016.09.029] [Medline: 27989291]

15. Nelson K, Schwartz G, Hernandez S, Simonetti J, Curtis I, Fihn SD. The association between neighborhood environment and mortality: results from a national study of veterans. J Gen Intern Med 2017 Apr;32(4):416-422 [FREE Full text] [doi: 10.1007/s11606-016-3905-x] [Medline: 27815763]

16. Katsaliaki K, Mustafee N. Applications of simulation within the healthcare context. J Oper Res Soc 2011;62(8):1431-1451 [FREE Full text] [doi: 10.1057/jors.2010.20] [Medline: 32226177]

17. Gusoff G. Professional medical association policy statements on social health assessments and interventions. Perm $\mathbf{J}$ 2018;22:18-92. [doi: 10.7812/tpp/18-092]

18. Friedman NL, Banegas MP. Toward addressing social determinants of health: a health care system strategy. Perm J 2018(22):18-95. [doi: 10.7812/TPP/18-095]

19. Kankanhalli A, Hahn J, Tan S, Gao G. Big data and analytics in healthcare: introduction to the special section. Inf Syst Front 2016 Mar 9;18(2):233-235. [doi: 10.1007/s10796-016-9641-2] 
20. World Health Organization. The Economics of Social Determinants of Health and Health Inequalities: A Resource Book. Geneva, Switzerland: World Health Organization; 2013.

21. Center for Prevention Services. Ten Leading Causes of Death in the United States. Atlanta, GA: Centers for Disease Control and Prevention; 1977.

22. McGinnis JM, Williams-Russo P, Knickman JR. The case for more active policy attention to health promotion. Health Aff (Millwood) 2002;21(2):78-93. [doi: 10.1377/hlthaff.21.2.78] [Medline: 11900188]

23. World Conference on Social Determinants of Health. World Health Organization. 2020. URL: http://www.who.int/ social determinants/sdhconference/background/en/ [accessed 2020-08-24]

24. Integrating Social Care Into the Delivery of Health Care: Moving Upstream to Improve the Nation's Health. Washington, DC: National Academies Press; 2019.

25. Guiding Principles for Ethical Use of Social Determinants of Health Data. EHealth Initiative. 2019. URL: https://www. ehidc.org/resources/guiding-principles-ethical-use-social-determinants-health-data [accessed 2019-10-27]

26. Nau C, Adams JL, Roblin D, Schmittdiel J, Schroeder E, Steiner JF. Considerations for identifying social needs in health care systems. Med Care 2019;57(9):661-666. [doi: 10.1097/mlr.0000000000001173]

27. Socioeconomic Health Scores. LexisNexis Risk Solutions. URL: https://risk.lexisnexis.com/products/ socioeconomic-health-score [accessed 2019-09-01]

28. Vest JR, Menachemi N, Grannis SJ, Ferrell JL, Kasthurirathne SN, Zhang Y, et al. Impact of risk stratification on referrals and uptake of wraparound services that address social determinants: a stepped wedged trial. Am J Prev Med 2019 Apr;56(4):e125-e133. [doi: 10.1016/j.amepre.2018.11.009] [Medline: 30772150]

29. Simpson M, Genovese A. Carrot Health - Leveraging Consumer Data to Grow Medicare Market Share. The Carrot MarketView. 2016. URL: https://info.carrothealth.com/hubfs/Brochures\%20and\%20Whitepapers/ Carrot\%20Health\%20-\%20Leveraging\%20Consumer\%20Data\%20to\%20Grow\%20Medicare\%20Market\%20Share. pdf? hstc $=122733652.515 \mathrm{~b} 5 \mathrm{~d} 9 \mathrm{ff} 7 \mathrm{a} 33417378 \mathrm{~b} 5 \mathrm{a} 218 \mathrm{fdca} 83 \mathrm{f} .1567383407805 .1567386846670 .1567398132639$.

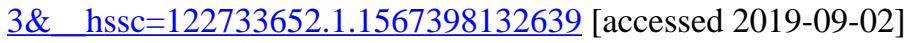

30. Predmore Z, Hatef E, Weiner JP. Integrating social and behavioral determinants of health into population health analytics: a conceptual framework and suggested road map. Popul Health Manag 2019 Dec;22(6):488-494. [doi: 10.1089/pop.2018.0151] [Medline: 30864884$]$

31. McGinnis T, Crumley D, Chang D. Implementing Social Determinants of Health Interventions in Medicaid Managed Care: How to Leverage Existing Authorities and Shift to Value-Based Purchasing. AcademyHealth. 2018. URL: https://www. academyhealth.org/sites/default/files/implementing sdoh medicaid managed care may2018.pdf [accessed 2019-09-24]

32. Matulis R, Lloyd J. The History, Evolution, and Future of Medicaid Accountable Care Organizations. Center for Health Care Strategies. 2020. URL: https://www.chcs.org/resource/history-evolution-future-medicaid-accountable-care-organizations/ [accessed 2020-08-24]

33. Artiga S, Hinton E. Beyond Health Care: The Role of Social Determinants in Promoting Health and Health Equity. Kaiser Family Foundation. 2018. URL: https://www.kff.org/disparities-policy/issue-brief/

beyond-health-care-the-role-of-social-determinants-in-promoting-health-and-health-equity/ [accessed 2019-09-08]

34. How Insurance Companies Set Health Premiums. HealthCare. URL: https://www.healthcare.gov/ how-plans-set-your-premiums/ [accessed 2020-05-12]

35. Chin T, Kahn R, Li R, Chen J, Krieger N, Buckee C, et al. US county-level characteristics to inform equitable COVID-19 response. medRxiv 2020 Apr 11:11 epub ahead of print [FREE Full text] [doi: 10.1101/2020.04.08.20058248] [Medline: $\underline{32511610]}$

36. Owen WF, Carmona R, Pomeroy C. Failing another national stress test on health disparities. J Am Med Assoc 2020 Apr 15;323(19):1905-1906 epub ahead of print. [doi: 10.1001/jama.2020.6547] [Medline: 32293642]

37. Cases in the US. Centers for Disease Control and Prevention. URL: https://www.cdc.gov/coronavirus/2019-ncov/ cases-updates/cases-in-us.html [accessed 2020-06-14]

38. Weekly Updates by Select Demographic and Geographic Characteristics: Provisional Death Counts for Coronavirus Disease 2019 (COVID-19). Centers for Disease Control and Prevention. 2020. URL: https://www.cdc.gov/nchs/nvss/vsrr/ covid weekly/index.htm [accessed 2020-06-14]

39. Wadhera RK, Wadhera P, Gaba P, Figueroa JF, Maddox KE, Yeh RW, et al. Variation in COVID-19 hospitalizations and deaths across New York City boroughs. J Am Med Assoc 2020 Apr 29;323(21):2192 [FREE Full text] [doi:

10.1001/jama.2020.7197] [Medline: $\underline{32347898]}$

40. Braithwaite R, Warren R. The African American petri dish. J Health Care Poor Underserved 2020;31(2):491-502. [doi: 10.1353/hpu.2020.0037]

41. Mapping High Risk Areas for COVID-19. Health Landscape. URL: https://www.healthlandscape.org/coronavirus/ [accessed 2020-06-14]

42. National Academies of Sciences. Accounting for Social Risk Factors in Medicare Payment: Criteria, Factors, and Methods. Washington, DC: National Academies of Sciences Engineering Medicine; 2016. 
43. Hatef E, Searle KM, Predmore Z, Lasser EC, Kharrazi H, Nelson K, et al. The impact of social determinants of health on hospitalization in the veterans health administration. Am J Prev Med 2019 Jun;56(6):811-818. [doi: 10.1016/j.amepre.2018.12.012] [Medline: $\underline{31003812]}$

44. Bhavsar NA, Gao A, Phelan M, Pagidipati NJ, Goldstein BA. Value of neighborhood socioeconomic status in predicting risk of outcomes in studies that use electronic health record data. JAMA Netw Open 2018 Sep 7;1(5):e182716 [FREE Full text] [doi: 10.1001/jamanetworkopen.2018.2716] [Medline: 30646172]

45. Brar Prayaga R, Agrawal R, Nguyen B, Jeong EW, Noble HK, Paster A, et al. Impact of social determinants of health and demographics on refill requests by medicare patients using a conversational artificial intelligence text messaging solution: cross-sectional study. JMIR Mhealth Uhealth 2019 Nov 18;7(11):e15771 [FREE Full text] [doi: 10.2196/15771] [Medline: 31738170]

46. Seligman B, Tuljapurkar S, Rehkopf D. Machine learning approaches to the social determinants of health in the health and retirement study. SSM Popul Health 2018 Apr;4:95-99 [FREE Full text] [doi: 10.1016/j.ssmph.2017.11.008] [Medline: 29349278]

47. Kasthurirathne S, Vest J, Menachemi N, Halverson P, Grannis S. Assessing the capacity of social determinants of health data to augment predictive models identifying patients in need of wraparound social services. J Am Med Inform Assoc 2018 Jan 1;25(1):47-53. [doi: 10.1093/jamia/ocx130] [Medline: 29177457]

48. Golembiewski E, Allen KS, Blackmon AM, Hinrichs RJ, Vest JR. Combining nonclinical determinants of health and clinical data for research and evaluation: rapid review. JMIR Public Health Surveill 2019 Oct 7;5(4):e12846 [FREE Full text] [doi: 10.2196/12846] [Medline: 31593550$]$

49. All-Payer Claims Databases. The Agency for Healthcare Research and Quality. 2017. URL: https://www.ahrq.gov/data/ apcd/index.html [accessed 2020-08-24]

50. Enhance Healthcare Analytics with Consumer Data. SlideShare. 2020. URL: https://www.slideshare.net/RayPun/ enhance-healthcare-analytics-with-consumer-data [accessed 2020-08-24]

51. Hatef E, Rouhizadeh M, Tia I, Lasser E, Hill-Briggs F, Marsteller J, et al. Assessing the availability of data on social and behavioral determinants in structured and unstructured electronic health records: a retrospective analysis of a multilevel health care system. JMIR Med Inform 2019 Aug 2;7(3):e13802 [FREE Full text] [doi: 10.2196/13802] [Medline: 31376277]

52. Guo Y, Zheng G, Fu T, Hao S, Ye C, Zheng L, et al. Assessing statewide all-cause future one-year mortality: prospective study with implications for quality of life, resource utilization, and medical futility. J Med Internet Res 2018 Jun 4;20(6):e10311 [FREE Full text] [doi: 10.2196/10311] [Medline: 29866643]

53. American Community Survey (ACS). US Census Bureau. URL: https://www.census.gov/programs-surveys/acs/ [accessed 2019-08-10]

54. Food Access Research Atlas. The Economics of Food, Farming, Natural Resources, and Rural America. URL: https://www. ers.usda.gov/data-products/food-access-research-atlas/ [accessed 2019-08-10]

55. Berkowitz SA, Basu S, Venkataramani A, Reznor G, Fleegler EW, Atlas SJ. Association between access to social service resources and cardiometabolic risk factors: a machine learning and multilevel modeling analysis. BMJ Open 2019 Mar 12;9(3):e025281 [FREE Full text] [doi: 10.1136/bmjopen-2018-025281] [Medline: 30862634]

56. American Housing Survey (AHS). US Census Bureau. URL: https://www.census.gov/programs-surveys/ahs.html [accessed 2019-08-11]

57. Hughes HK, Matsui EC, Tschudy MM, Pollack CE, Keet CA. Pediatric asthma health disparities: race, hardship, housing, and asthma in a national survey. Acad Pediatr 2017 Mar;17(2):127-134 [FREE Full text] [doi: 10.1016/j.acap.2016.11.011] [Medline: 27876585]

58. Goldstein BA, Navar AM, Pencina MJ, Ioannidis JP. Opportunities and challenges in developing risk prediction models with electronic health records data: a systematic review. J Am Med Inform Assoc 2017 Jan;24(1):198-208 [FREE Full text] [doi: 10.1093/jamia/ocw042] [Medline: 27189013]

59. Schroeder EB, Xu S, Goodrich GK, Nichols GA, O'Connor PJ, Steiner JF. Predicting the 6-month risk of severe hypoglycemia among adults with diabetes: development and external validation of a prediction model. J Diabetes Complications 2017 Jul;31(7):1158-1163 [FREE Full text] [doi: 10.1016/j.jdiacomp.2017.04.004] [Medline: 28462891]

60. FAQ. AllTransit. URL: https://alltransit.cnt.org/faq/ [accessed 2019-08-11]

61. Air Quality Index Report. United States Environmental Protection Agency: US EPA. URL: https://www.epa.gov/ outdoor-air-quality-data/air-quality-index-report [accessed 2019-08-11]

62. Food Access Research Atlas. The Economics of Food, Farming, Natural Resources, and Rural America. URL: https://www. ers.usda.gov/data-products/food-access-research-atlas/ [accessed 2019-10-25]

63. Grinspan ZM, Patel AD, Hafeez B, Abramson EL, Kern LM. Predicting frequent emergency department use among children with epilepsy: a retrospective cohort study using electronic health data from 2 centers. Epilepsia 2018 Jan;59(1):155-169 [FREE Full text] [doi: 10.1111/epi.13948] [Medline: 29143960]

64. Chaiyachati KH, Hubbard RA, Yeager A, Mugo B, Lopez S, Asch E, et al. Association of rideshare-based transportation services and missed primary care appointments: a clinical trial. JAMA Intern Med 2018 Mar 1;178(3):383-389. [doi: 10.1001/jamainternmed.2017.8336] [Medline: 29404572] 
65. Bresnick J. Social Determinants of Health Dashboard Expands to 500 Cities. HealthITAnalytics. URL: https://healthitanalytics. com/news/social-determinants-of-health-dashboard-expands-to-500-cities [accessed 2019-09-02]

66. 500 Cities: Local Data for Better Health. Centers for Disease Control and Prevention. URL: https://www.cdc.gov/500cities/ index.htm [accessed 2019-09-02]

67. Bringing Consumerism to Healthcare: Powered by Social and Behavioral Determinants of Health (SDoH). Carrot Health. URL: https://carrothealth.com/wp-content/uploads/2018/04/MarketView-For-Payers.pdf [accessed 2019-11-09]

68. Benaroya R. Health Plan Member Engagement Strategies That Improve Satisfaction and Outcomes. Cecelia Health. 2020. URL: https://www.ceceliahealth.com/blog/health-plan-member-engagement-strategies-that-improve-satisfaction-and-outcomes [accessed 2020-08-24]

69. Hutson M. Artificial intelligence faces reproducibility crisis. Science 2018 Feb 16;359(6377):725-726. [doi: 10.1126/science.359.6377.725] [Medline: 29449469]

70. Christopher V, Rao D, Giabbanelli P. How Do Modelers Code Artificial Societies? Investigating Practices and Quality of Netlogo Codes from Large Repositories. In: Spring Simulation Conference. 2020 Presented at: SS'20; March 29-April 1, 2020; Fairfax, VA, USA. [doi: 10.22360/springsim.2020.hsaa.007]

71. Collins GS, Reitsma JB, Altman DG, Moons KG. Transparent reporting of a multivariable prediction model for individual prognosis or diagnosis (TRIPOD). Ann Intern Med 2015 May 19;162(10):735-773. [doi: 10.7326/115-5093-2]

72. Wharam J, Weiner J. The promise and peril of healthcare forecasting. Am J Manag Care 2012 Mar 1;18(3):e82-e85 [FREE Full text] [Medline: 22435964]

73. Copeland R. Google's 'Project Nightingale' Gathers Personal Health Data on Millions of Americans. The Wall Street Journal. 2019. URL: https://www.wsj.com/articles/ google-s-secret-project-nightingale-gathers-personal-health-data-on-millions-of-americans-11573496790 [accessed 2019-11-14]

74. Steiner J, Clift M, Nau C, Schroeder E. Issue Brief: Survey Results Update. SONNET. 2018. URL: https://sonnet. kaiserpermanente.org/products.html [accessed 2020-08-24]

75. McGraw D. Privacy concerns related to inclusion of social and behavioral determinants of health in electronic health records. In: Capturing Social and Behavioral Domains and Measures in Electronic Health Records: Phase 2. Washington, DC: The National Academies Press; 2015.

76. Cohen IG, Amarasingham R, Shah A, Xie B, Lo B. The legal and ethical concerns that arise from using complex predictive analytics in health care. Health Aff (Millwood) 2014 Jul;33(7):1139-1147. [doi: 10.1377/hlthaff.2014.0048] [Medline: 25006139]

77. Amarasingham R, Patzer RE, Huesch M, Nguyen NQ, Xie B. Implementing electronic health care predictive analytics: considerations and challenges. Health Aff (Millwood) 2014 Jul;33(7):1148-1154. [doi: 10.1377/hlthaff.2014.0352] [Medline: $\underline{25006140]}$

78. Beier K, Schweda M, Schicktanz S. Taking patient involvement seriously: a critical ethical analysis of participatory approaches in data-intensive medical research. BMC Med Inform Decis Mak 2019 Apr 25;19(1):90 [FREE Full text] [doi: 10.1186/s12911-019-0799-7] [Medline: 31023321]

79. Japkowicz N, Stephen S. The class imbalance problem: a systematic study. Intell Data Anal 2002;6(5):429-449. [doi: 10.3233/ida-2002-6504]

80. Obermeyer Z, Powers B, Vogeli C, Mullainathan S. Dissecting racial bias in an algorithm used to manage the health of populations. Science 2019 Oct 25;366(6464):447-453. [doi: 10.1126/science.aax2342] [Medline: 31649194]

81. White S. A review of big data in health care: challenges and opportunities. Open Access Bioinforma Macclesfield 2014 Oct:13. [doi: 10.2147/oab.s50519]

82. Oreskovic NM, Maniates J, Weilburg J, Choy G. Optimizing the use of electronic health records to identify high-risk psychosocial determinants of health. JMIR Med Inform 2017 Aug 14;5(3):e25 [FREE Full text] [doi: 10.2196/medinform.8240] [Medline: 28807893]

83. Kind AJ, Jencks S, Brock J, Yu M, Bartels C, Ehlenbach W, et al. Neighborhood socioeconomic disadvantage and 30-day rehospitalization: a retrospective cohort study. Ann Intern Med 2014 Dec 2;161(11):765-774 [FREE Full text] [doi: 10.7326/M13-2946] [Medline: 25437404]

84. Bazemore A, Cottrell E, Gold R, Hughes L, Phillips R, Angier H, et al. 'Community vital signs': incorporating geocoded social determinants into electronic records to promote patient and population health. J Am Med Inform Assoc 2016 Mar;23(2):407-412. [doi: 10.1093/jamia/ocv088] [Medline: 26174867]

85. Haining R. Spatial autocorrelation. In: Smelser NJ, Baltes PB, editors. International Encyclopedia of Social \& Behavioral Sciences. Oxford, UK: Pergamon; 2001.

86. Chancellor L, Baijal S. Optimizing Healthcare Analytics: How to Choose the Right Predictive Model. EXL Service, Digital Intelligence, Analytics \& Operations. URL: https://www.exlservice.com/resources/assets/library/documents/ EXL WP HC OptimizingHealthcareAnalytics.pdf [accessed 2020-08-12]

87. Dhar V. Big data and predictive analytics in health care. Big Data 2014 Sep;2(3):113-116. [doi: 10.1089/big.2014.1525] [Medline: 27442491] 
88. Steiner JF, Stenmark SH, Sterrett AT, Paolino AR, Stiefel M, Gozansky WS, et al. Food insecurity in older adults in an integrated health care system. J Am Geriatr Soc 2018 May;66(5):1017-1024. [doi: 10.1111/jgs.15285] [Medline: 29492953]

89. Shah ND, Steyerberg EW, Kent DM. Big data and predictive analytics: recalibrating expectations. J Am Med Assoc 2018 Jul 3;320(1):27-28. [doi: 10.1001/jama.2018.5602] [Medline: 29813156]

90. Phelan J, Link B. Controlling disease and creating disparities: a fundamental cause perspective. J Gerontol B Psychol Sci Soc Sci 2005 Oct;60(Spec No 2):27-33. [doi: 10.1093/geronb/60.special issue 2.s27] [Medline: 16251587]

91. Amarasingham R, Audet AJ, Bates DW, Cohen IG, Entwistle M, Escobar GJ, et al. Consensus statement on electronic health predictive analytics: a guiding framework to address challenges. EGEMS (Wash DC) 2016;4(1):1163 [ㅍEE Full text] [doi: 10.13063/2327-9214.1163] [Medline: 27141516]

92. Ross TR, Ng D, Brown JS, Pardee R, Hornbrook MC, Hart G, et al. The HMO research network virtual data warehouse: a public data model to support collaboration. EGEMS (Wash DC) 2014;2(1):1049 [FREE Full text] [doi:

10.13063/2327-9214.1049] [Medline: 25848584]

93. Research Data Sharing Without Barriers. Research Data Alliance. URL: https://www.rd-alliance.org/ [accessed 2020-08-12]

94. Freij M, Dullabh P, Lewis S, Smith SR, Hovey L, Dhopeshwarkar R. Incorporating social determinants of health in electronic health records: qualitative study of current practices among top vendors. JMIR Med Inform 2019 Jun 7;7(2):e13849 [FREE Full text] [doi: 10.2196/13849] [Medline: 31199345]

95. The Gravity Project: A National Collaborative to Advance Interoperable Social Determinants of Health Data. UCSF Siren. URL: https://sirenetwork.ucsf.edu/TheGravityProject [accessed 2019-10-13]

96. Glass TA, McAtee MJ. Behavioral science at the crossroads in public health: extending horizons, envisioning the future. Soc Sci Med 2006 Apr;62(7):1650-1671. [doi: 10.1016/j.socscimed.2005.08.044] [Medline: 16198467]
Abbreviations
CDC: Centers for Disease Control and Prevention
EHR: electronic health record
NLP: natural language processing
SBDH: social and behavioral determinants of health
TRIPOD: Transparent Reporting of a multivariate prediction model for Individual Prognosis or Diagnosis

\author{
Edited by C Lovis; submitted 02.02.20; peer-reviewed by J Steiner, J op den Buijs, P Giabbanelli; comments to author 06.05.20; \\ revised version received 17.06.20; accepted 20.07.20; published 08.09.20 \\ Please cite as: \\ Tan M, Hatef E, Taghipour D, Vyas K, Kharrazi H, Gottlieb L, Weiner J \\ Including Social and Behavioral Determinants in Predictive Models: Trends, Challenges, and Opportunities \\ JMIR Med Inform 2020;8(9):e18084 \\ URL: http://medinform.jmir.org/2020/9/e18084/ \\ doi: $10.2196 / 18084$ \\ PMID: 32897240
}

CMarissa Tan, Elham Hatef, Delaram Taghipour, Kinjel Vyas, Hadi Kharrazi, Laura Gottlieb, Jonathan Weiner. Originally published in JMIR Medical Informatics (http://medinform.jmir.org), 08.09.2020. This is an open-access article distributed under the terms of the Creative Commons Attribution License (https://creativecommons.org/licenses/by/4.0/), which permits unrestricted use, distribution, and reproduction in any medium, provided the original work, first published in JMIR Medical Informatics, is properly cited. The complete bibliographic information, a link to the original publication on http://medinform.jmir.org/, as well as this copyright and license information must be included. 